J Am Chem Soc. 2019 June 05; 141(22): 8708-8711. doi:10.1021/jacs.9b03438.

\title{
Enantioselective Markovnikov Addition of Carbamates to Allylic Alcohols for the Construction of a-Secondary and a-Tertiary Amines
}

\author{
Ana Bahamonde $\ddagger$, Buthainah Al Rifaie ${ }^{\ddagger}$, Victor Martín-Heras, Jamie R. Allen, and Matthew \\ S. Sigman* \\ Department of Chemistry, University of Utah, 315 S 1400 E, Salt Lake City, UT 84112, United \\ States
}

\begin{abstract}
Herein we describe the development of a Pd-catalyzed enantioselective Markovnikov addition of carbamates to allylic alcohols for the construction of a-tertiary and a-secondary amines. The reaction affords a range of $\beta$-amino alcohols, after reduction of the aldehyde in situ, which contain a variety of functional groups in moderate yields and moderate to good enantioselectivities. These products can be readily oxidized to $\beta$-amino acids, valuable building blocks for the synthesis of biologically active compounds. Mechanistic studies indicate that $\mathrm{C}-\mathrm{N}$ bond formation occurs via a syn amino-palladation mechanism, an insight which may guide future reaction development given the limited number of enantioselective syntheses of a-tertiary amines.
\end{abstract}

\section{Graphical Abstract}

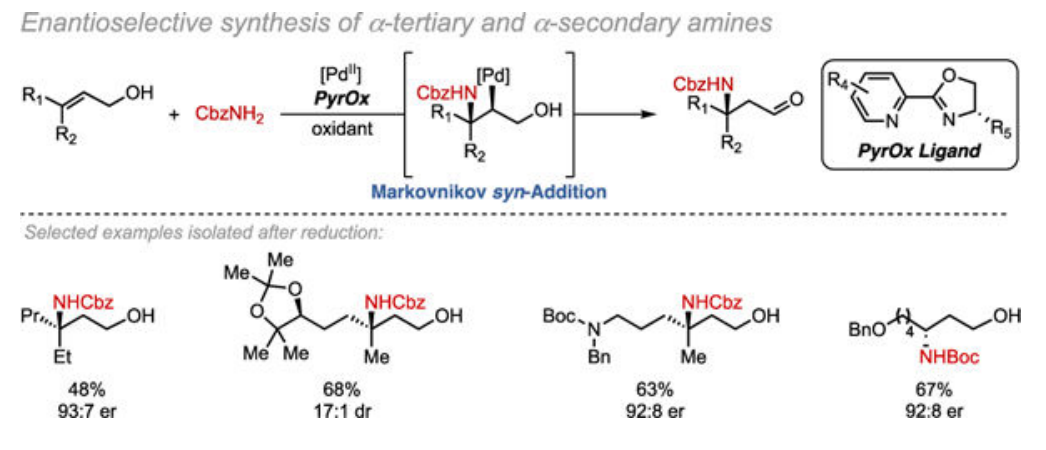

\begin{abstract}
Owing to the ubiquity of chiral alkyl amines in natural products and pharmaceuticals, methods for constructing $\mathrm{C}-\mathrm{N}$ bonds in a catalytic enantioselective manner are of great value. ${ }^{1}$ While a number of enantioselective approaches for the generation of chiral amines have been reported, in the context of our studies, the most relevant transformation is alkene
\end{abstract}

\footnotetext{
"Corresponding Author sigman@chem.utah.edu.

₹Author Contributions These authors contributed equally. ASSOCIATED CONTENT

Supporting Information

Experimental procedures, compound characterization, and NMR spectra. This material is free of charge via the Internet at http:// pubs.acs.org.

The authors declare no competing financial interests.
} 
hydroamination. ${ }^{1,2}$ This direct and efficient method to form $\mathrm{C}-\mathrm{N}$ bonds often eliminates the necessity for prior functionalization of the starting materials and uses readily available synthetic precursors. Perhaps the most synthetically useful advances are highlighted by the recent reports of $\mathrm{Cu}$-catalyzed hydroamination of activated olefins (i.e., styrenes), which provide aliphatic amines in high yields and enantioselectivities. ${ }^{2,3}$ Expansion of this methodology to the use of unactivated 1,2-disubstituted alkenes has been realized by the Buchwald group (Figure 1A). ${ }^{4}$ Elegant mechanistic investigations of this reaction have revealed the critical role of attractive dispersive interactions between the bulky bidentate phosphine ligands and the olefin substituents in the consequential anti-Markovnikov hydrocupration step (intermediate A, Figure 1) ${ }^{5}$ These insights expose why the method is sensitive to steric effects on the alkene with only effective catalysis presented for 1,2disubstituted alkenes to access $a$-secondary amines to date.

In order to access a-tertiary amines using a hydroamination strategy, a Markovnikov addition to trisubstituted alkenes would be required, which has not been reported. An inspiration to develop such a method originates from the prevalence of chiral a-tertiary amines in alkaloids and biologically active compounds. ${ }^{6}$ Indeed, these highly congested amines cannot be accessed using any of the most commonly used enantioselective approaches ${ }^{1,2}$ and are currently accessed via indirect strategies such as reduction of $N$ sulfonyloxaziridines, ${ }^{7}$ or diastereoselective intramolecular cyclizations. ${ }^{6}$ Ideally, the development of a catalytic enantioselective strategy would be both complementary and enabling.

In this context, we envisioned that a transition metal-catalyzed enantioselective addition of amines to trisubstituted olefins in a Markovnikov fashion may be possible using an azaWacker-type process. ${ }^{8}$ This strategy was inspired by our recently reported $\mathrm{Pd} / \mathrm{PyrOx}$ catalyzed intermolecular addition of phenols to disubstituted allylic alcohols. ${ }^{9} \mathrm{We}$ hypothesized that a related catalytic system could enable the coupling of carbamates to triand di-substituted allylic alcohols to generate $\beta$-amino aldehydes (3, Figure 1B). These products are particularly interesting as they can be readily oxidized to form $\beta$-amino acids, which are common chiral building blocks. ${ }^{10}$ Additionally, $\beta$-amino acids are common precursors $\beta$-lactams. ${ }^{11}$ Notably, the intermolecular addition of phenols or other heteroatom nucleophiles to trisubstituted alkenes have not been reported in an enantioselective fashion.

Mechanistically, this aza-Wacker-type ${ }^{8}$ reaction would involve a key Pd(II)-catalyzed Markovnikov addition to a trisubstituted allylic alcohol (intermediate C, Figure 1B). Studies of enantioselective intramolecular aza-Wacker reactions have shown that this aminopalladation step can occur via two different mechanisms: syn- and antiaminopalladation. ${ }^{12}$ The nature of this $\mathrm{C}-\mathrm{N}$ bond-forming process may generate opposite enantiomers of product and has been shown to be highly dependent on the reaction conditions, particularly with respect to the amine nucleophile and catalyst employed. ${ }^{13}$ Consequently, exquisite control of the aminopalladation event is likely required to achieve high levels of enantioselectivity. Subsequent $\beta$-hydride elimination and reinsertion would render intermediate $\mathbf{E}$, which can undergo elimination to form a $\operatorname{Pd}(0)$ complex and release the desired product $3 .{ }^{14}$ The catalytic cycle is completed by oxidation of the $\operatorname{Pd}(0)$ species to regenerate the $\mathrm{Pd}(\mathrm{II})$ catalyst. 
Our optimization studies began by selecting trisubstituted allylic alcohol 1a and benzyl carbamate $\mathbf{2 a}$ as the model substrate and nitrogen nucleophile, respectively (Table 1). This amine source is viewed as particularly attractive because $\mathrm{Cbz}$ is commonly used as a protecting group in peptide coupling chemistry and can be readily removed. Initial evaluation of our previously developed catalyst system for the enantioselective Wacker-type phenol addition to allylic alcohols unfortunately resulted in a $6 \%$ yield (entry 1$).{ }^{9}$ Through substantial evaluation of the reaction conditions, the combination of $\mathrm{CHCl}_{3}$ as solvent and $p$ benzoquinone (BQ) as the terminal oxidant resulted in $31 \%$ yield and $87: 13 \mathrm{er}$ of desired product 3a (entry 2). An enhancement in yield was observed when one equivalent of an organic base, 2,6-di-tert-butyl-4-methylpyridine (DTBMP), was added (entry 3). Notably, switching the oxidant from $\mathrm{BQ}$ to a $\mathrm{Cu}$ (II) salt under an aerobic atmosphere produced the desired product in significantly diminished yield (entry 4). Aiming to improve the moderate enantioselectivity (87:13 er) of the process, a series of PyrOx ligands were evaluated (see SI for more details). ${ }^{15}$ While $\mathbf{L} \mathbf{3}$ promoted this reaction in a higher er value (92:8), the reaction yield decreased (entry 5). Careful examination of this result revealed that the ligand is consumed under the reaction conditions. Increasing the ligand loading or adding more ligand after its consumption resulted in similar observations (entry 6). Interestingly, when the catalyst loading is reduced by half, a higher turnover number is obtained. Taking advantage of this observation, the reaction was carried out with the sequential addition of 3 batches of $3 \mathrm{~mol} \% \mathrm{Pd}$ and $6 \mathrm{~mol} \% \mathbf{L 3}$, which resulted in an isolated yield of 66\% and 92:8 er of the desired product (entry 8). The importance of multiple catalyst additions is illustrated in entries 8 and 9 wherein superior yields are obtained in comparison to a single addition of the catalyst. Unfortunately, using an excess of the carbamate (2a), a ratio of 3:1 carbamate:olefin, the yield decreased to a $43 \%$ (not shown).

Considering the uniqueness of the Markovnikov addition of a carbamate to a trisubstituted alkene and the previously reported dependence of the aminopalladation mechanism on the reaction components, ${ }^{12}$ deuterated allylic alcohol $\mathbf{1 e}-\boldsymbol{d}_{2}$ was subjected to the optimized conditions (Figure 2) to study the mode of insertion (syn or anti). Based on the assumption that the Pd does not dissociate from the alkene after the aminopalladation event, ${ }^{14}$ the relative stereochemistry between the deuterium and the amine is set by the nature of this step. As a result, the relative stereochemistry of the diastereomer formed would relate to the mechanism of the $\mathrm{C}-\mathrm{N}$ bond formation. To accurately determine the stereochemical outcome of the reaction, the amino aldehyde was converted into cyclic carbamate 4 following the route depicted in Figure 2b. A cis relationship between the deuterium and the benzyl group in compound $\mathbf{4}$ was determined by $1 \mathrm{D}$-nOe suggesting that the reaction proceeds via a $s y n$-aminopalladation mechanism.

As the next stage, we examined the scope of compatible allylic alcohols (Table 2A). ${ }^{16} \mathrm{~A}$ series of different alkyl and remote aryl substituents were evaluated with no significant effect on the enantioselectivity or yield of the process $(\mathbf{3 b}-\mathbf{3 e})$. The aldehyde products were reduced to the corresponding alcohols (3) to facilitate the isolation process and avoid product decomposition. It is notable that the catalyst can discriminate between an ethyl and a propyl group to yield $\mathbf{3 d}$ with a good level of enantioselectivity. Functional group tolerance was examined by incorporating a second olefin (3f), an acetonide (3g, 3h), a silyl-protected 
alcohol (3i), an alkyl tosylate (3j), a chloride (3k), and an orthogonally protected amine (3i). In all cases, the reaction performs similarly to the model substrate wherein the amino alcohols are isolated in moderate yields with moderate to high enantioselectivities. Enantiomerically enriched substrates $\mathbf{2 g}$ and $\mathbf{2 h}$ were subjected to the reaction conditions resulting in excellent diastereoselectivities and good yields (3g and $\mathbf{3 h}) .{ }^{17}$ The stereocenter established by the enantioselective aza-Wacker process is conserved suggesting that the reaction is under complete catalyst control in the $\mathrm{C}-\mathrm{N}$ bond forming event.

To further explore the scope, disubstituted olefins were also evaluated. Similar conditions were found to be optimal although no improvement on the reaction yield is observed using a portion-wise addition. Additionally, PyrOx ligand $\mathbf{L} 4$ was selected to probe the substrate scope of disubstituted alkenols as lower enantioselectivity was obtained using ligand $\mathbf{L 3}$ (er $=84: 16$ ). Moderate yields and good levels of enantioselectivity in the reaction were obtained when olefins containing different alkyl groups, including the more sterically demanding cyclohexyl moiety, were employed (entries 3m-3p, Table 2B). Functional group tolerance was evaluated using protected alcohol 1q, and nitrile 1r. In both cases, the final product is obtained in a good er (3q and $\mathbf{3 r}$ ); however, the use of a nitrile resulted in diminished yield. The absolute stereochemistry of the aminated product $\mathbf{3 m}$ was unambiguously assigned to be $(R)$ via X-ray crystallography of a derivative. The preferential formation of the $(R)$ enantiomer when a Z-alkenol is used, together with the syn-palladation mechanism, are consistent with the stereochemical models proposed in the redox-relay Heck reactions previously reported by our group. ${ }^{14 \mathrm{a}}$

As noted in the introduction, this reaction allows access to $\alpha$-tertiary and $\alpha$-secondary $\beta$ amino acids. Therefore, a selection of amino alcohols products $(\mathbf{3})$ from the aza-Wacker reaction were oxidized to the $\beta$-amino acids $\mathbf{5}$ in near quantitative yields, with no significant erosion of the enantiomeric ratio (Table 3 ). ${ }^{18}$

In summary, we have developed a Markovnikov addition of carbamates to tri- and disubstituted olefins. This Pd-catalyzed reaction generates $a$-tertiary and $a$-secondary $\beta$ amino alcohols in moderate yields and moderate to good enantioselectivities, from which facile oxidation permits access to $\beta$-amino acids. An isotopic labeling experiment suggests that this bond formation occurs via a syn-aminopalladation pathway, an important insight given the established sensitivity of aminopalladation mechanism to reaction conditions in related intramolecular aza-Wacker reactions. ${ }^{12}$ Further mechanistic investigations are currently ongoing in our laboratory, as we envision that this methodology will inspire future studies of the asymmetric synthesis of a-tertiary heteroatom stereocenters.

\section{Supplementary Material}

Refer to Web version on PubMed Central for supplementary material.

\section{ACKNOWLEDGMENT}

The work was supported by National Institute of Health (NIGMS R01GM063540). B. A. R. thanks the NSF for a predoctoral fellowship. We thank Dr. Ryan VanderLinden for solving the crystal structure. 


\section{REFERENCES}

(1). (a)Li W; Zhang X Stereoselective Formation of Amines, Vol. 343 of Topics in Current Chemistry Springer: Berlin, 2014.(b)Nugent TC Chiral amine synthesis: methods, developments and applications John Wiley \& Sons, 2010.(c)Ricci A Modern Amination Methods Wiley: Weinheim, 2008.

(2). (a)Muller TE; Hultzsch KC; Yus M; Foubelo F; Tada M, Hydroamination: direct addition of amines to alkenes and alkynes. Chem. Rev 2008, 108, 3795-3892. [PubMed: 18729420] (b)Pirnot MT; Wang YM; Buchwald SL, Copper hydride catalyzed hydroamination of alkenes and alkynes. Angew. Chem. Int. Ed 2016, 55, 48-57.

(3). For seminal reports see: (a) Miki Y; Hirano K; Satoh T; Miura M, Copper-Catalyzed Intermolecular Regioselective Hydroamination of Styrenes with Polymethylhydrosiloxane and Hydroxylamines. Angew. Chem. Int. Ed 2013, 52, 10830-10834.(b)Zhu S; Niljianskul N; Buchwald SL, Enantio-and regioselective CuH-catalyzed hydroamination of alkenes. J. Am. Chem. Soc 2013, 135, 15746-15749. [PubMed: 24106781]

(4). (a)Yang Y; Shi SL; Niu D; Liu P; Buchwald SL, Catalytic asymmetric hydroamination of unactivated internal olefins to aliphatic amines. Science 2015, 349, 62-66. [PubMed: 26138973] (b)For an example of a directing group-mediated variant, see: Xi Y; Butcher TW; Zhang J; Hartwig JF, Regioselective, asymmetric formal hydroamination of unactivated internal alkenes. Angew. Chem. Int. Ed 2016, 55, 776-780.

(5). Lu G; Liu RY; Yang Y; Fang C; Lambrecht DS; Buchwald SL; Liu P, Ligand-Substrate Dispersion Facilitates the Copper-Catalyzed Hydroamination of Unactivated Olefins. J. Am. Chem. Soc 2017, 139, 16548-16555. [PubMed: 29064694]

(6). Hager A; Vrielink N; Hager D; Lefranc J; Trauner D, Synthetic approaches towards alkaloids bearing a-tertiary amines. Nat. Prod. Rep 2016, 33, 491-522. [PubMed: 26621771]

(7). Davis FA, Adventures in sulfur-nitrogen chemistry. J. Org. Chem 2006, 71, 8993-9003. [PubMed: 17109522]

(8). (a)Hosokawa T; Takano M; Kuroki Y; Murahashi S-I, Palladium(II)-catalyzed amidation of alkenes. Tetrahedron Lett 1992, 33, 6643-6646.(b)Yang G; Shen C; Zhang W, An Asymmetric Aerobic Aza-Wacker-Type Cyclization: Synthesis of Isoindolinones Bearing Tetrasubstituted Carbon Stereocenters. Angew. Chem. Int. Ed 2012, 51, 9141-9145.(c)White DR; Hutt JT; Wolfe JP, Asymmetric Pd-Catalyzed Alkene Carboamination Reactions for the Synthesis of 2Aminoindane Derivatives. J. Am. Chem. Soc 2015, 137, 11246-11249. [PubMed: 26313846] (d)Overman LE; Remarchuk TP, Catalytic Asymmetric Intramolecular Aminopalladation: Enantioselective Synthesis of Vinyl-Substituted 2-Oxazolidinones, 2-Imidazolidinones, and 2Pyrrolidinones. J. Am. Chem. Soc 2002, 124, 12-13. [PubMed: 11772049] (e)Neukom JD; Perch NS; Wolfe JP, Intramolecular Alkene Aminopalladation Reactions of (dppf)Pd(Ar)[N(Ar1) $(\mathrm{CH} 2) 3 \mathrm{CH}=\mathrm{CH} 2$ ] Complexes. Insertion of Unactivated Alkenes into Pd-N Bonds. J. Am. Chem. Soc 2010, 132, 6276-6277. [PubMed: 20397666] (f)Kotov V; Scarborough CC; Stahl SS, Palladium-Catalyzed Aerobic Oxidative Amination of Alkenes: Development of Intra- and Intermolecular Aza-Wacker Reactions. Inorg. Chem 2007, 46, 1910-1923. [PubMed: 17348722]

(9). Race NJ; Schwalm CS; Nakamuro T; Sigman MS, Palladium-Catalyzed Enantioselective Intermolecular Coupling of Phenols and Allylic Alcohols. J. Am. Chem. Soc 2016, 138, 1588115884. [PubMed: 27960316]

(10). (a)Nussbaum F; Spiteller P Highlights in Bioorganic Chemistry: Methods and Application Schmuck C; Wennemers H Eds.; Wiley-VCH: Weinheim, 2004, p. 63(b)Juaristi E; Soloshonok VA Enantioselective synthesis of $\beta$-amino acids John Wiley \& Sons, 2005.(c)Weiner B; Szymański W; Janssen DB; Minnaard AJ; Feringa BL, Recent advances in the catalytic asymmetric synthesis of $\beta$-amino acids. Chem. Soc. Rev 2010, 39, 1656-1691. [PubMed: 20419214] (d)Cardillo G; Tomasini C, Asymmetric synthesis of $\beta$-amino acids and $\alpha$-substituted $\beta$-amino acids. Chem. Soc. Rev 1996, 25, 117-128.(e)Magriotis PA, Recent Progress in the Enantioselective Synthesis of $\beta$-Lactams: Development of the First Catalytic Approaches. Angew. Chem. Int. Ed 2001, 40, 4377-4379.(f)Hamuro Y Schneider PJ; DeGrado FWJ, The twists and turns of $\beta$-peptides. Peptide Res 1999, 54, 206-217. 
(11). (a)Magriotis PA, Recent Progress in the Enantioselective Synthesis of $\beta$-Lactams: Development of the First Catalytic Approaches. Angew. Chem. Int. Ed, 2001, 40, 4377-4379.(b)Singh GS, Recent progress in the synthesis and chemistry of azetidinones. Tetrahedron 2003, 59, 76317649.(c)Brandi A; Cicchi S; Cordero FM, Novel syntheses of azetidines and azetidinones. Chem. Rev 2008, 108, 3988-4035. [PubMed: 18781723]

(12). (a)Kocovsky P; Baeckvall J-E, The syn/anti-dichotomy in the palladium-catalyzed addition of nucleophiles to alkenes. Chem. Eur. J 2015, 21, 36-56. [PubMed: 25378278] (b)Weinstein AB; Stahl SS, Reconciling the Stereochemical Course of Nucleopalladation with the Development of Enantioselective Wacker-Type Cyclizations. Angew. Chem. Int. Ed 2012, 124, 11673-11677.

(13). McDonald RI; White PB; Weinstein AB; Tam CP; Stahl SS, Enantioselective Pd(II)-Catalyzed Aerobic Oxidative Amidation of Alkenes and Insights into the Role of Electronic Asymmetry in Pyridine-Oxazoline Ligands. Org. Lett 2011, 13, 2830-2833. [PubMed: 21534607]

(14). (a)Xu L; Hilton MJ; Zhang X; Norrby P-O; Wu Y-D; Sigman MS; Wiest O, Mechanism, Reactivity, and Selectivity in Palladium-Catalyzed Redox-Relay Heck Arylations of Alkenyl Alcohols. J. Am. Chem. Soc 2014, 136, 1960-1967. [PubMed: 24410393] (b)Hilton MJ; Xu L-P; Norrby P-O; Wu Y-D; Wiest O; Sigman MS, Investigating the Nature of Palladium ChainWalking in the Enantioselective Redox-Relay Heck Reaction of Alkenyl Alcohols. J. Org. Chem 2014, 79, 11841-11850. [PubMed: 25186804]

(15). Yang G; Zhang W, Renaissance of pyridine-oxazolines as chiral ligands for asymmetric catalysis. Chem. Soc. Rev 2018, 47, 1783-1810. [PubMed: 29469141]

(16). For scope limitations and other amination examples please refer to the SI.

(17). Xu D; Park CY; Sharpless KB, Xu, Daqiang, Christine Y Park, and K. Barry Sharpless. Study of the regio- and enantioselectivity of the reactions of osmium tetroxide with allylic alcohols and allylic sulfonamides. Tetrahedron Lett 1994, 35, 2495-2498.

(18). Sabala R; Hernández J; Carranza V; Meza-León RL; Bernès S, Sansinenea E; Ortiz A, Rearrangement of oxazolidinethiones to thiazolidinediones or thiazinanediones and their application for the synthesis of chiral allylic ureas and a-methyl- $\beta$-amino acids. Tetrahedron 2010, 66, 111-120. 
A: Hydroamination of 1,2-disusbstituted olefins to access $\alpha$-secondary amines (ref 3)

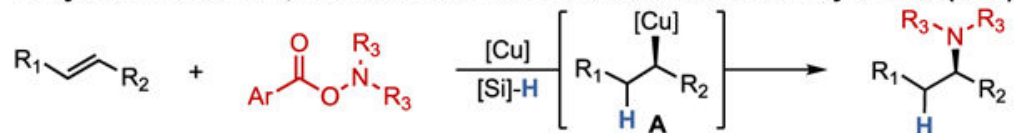

B: Our approach to $\alpha$-tertiary amines
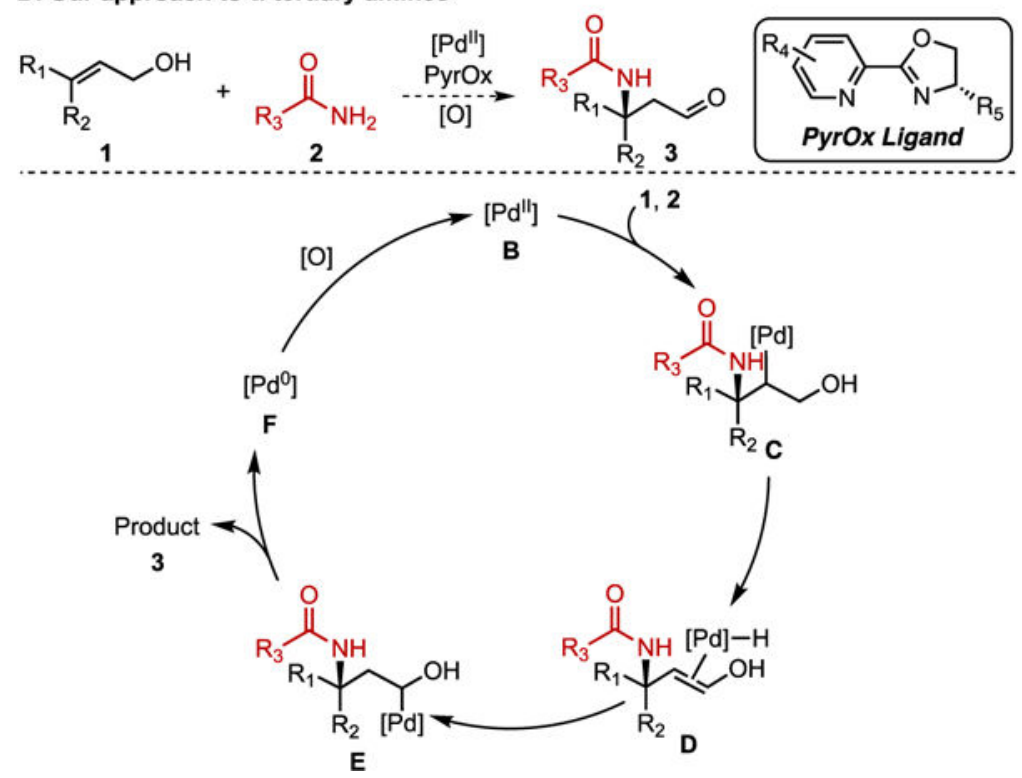

Figure 1.

Enantioselective coupling of amines to olefins. 
A: Syn- and anti-addition mechanisms

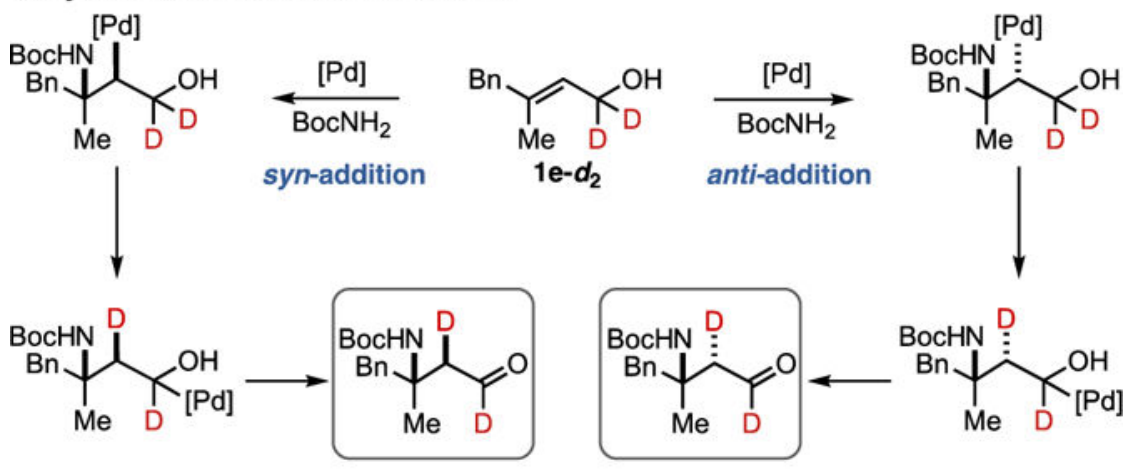

B: Assignment of the relative stereochemistry

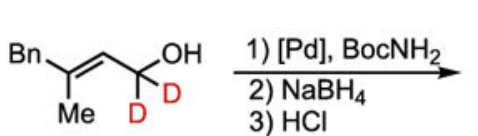

$1 \mathrm{e}-d_{2}$

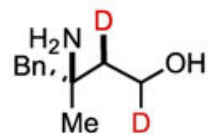

syn-addition

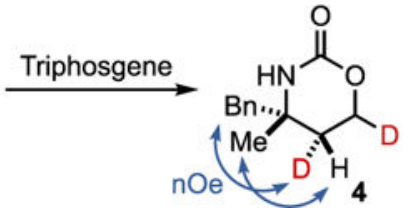

Figure 2.

Aminopalladation mechanistic studies 


\section{Table 1:}

Optimization of reaction conditions $\mathrm{s}^{\mathrm{a}}$

${ }^{a}$ Reactions were run on a 0.2 mmol scale. Yields were determined by ${ }^{1} \mathrm{H}$ NMR spectroscopy using $1,3,5-$ trimethoxybenze as internal standard. Enantiomeric ratios were determined by $\mathrm{SFC} .{ }^{b} \mathrm{PhCF}_{3}$ used as solvent, carbamate 2a (2 equiv) and alkene 1a (1 equiv). ${ }^{d} \mathrm{Pd}\left(\mathrm{CH}_{3} \mathrm{CN}\right)_{2}(\mathrm{OTs})_{2}$ and $\mathbf{L 3}$ were added in 3 batches of 3 mol $\%$ and $6 \mathrm{~mol} \%$ respectively. ${ }^{e}$ Yields in parentheses are of isolated material after reduction to the alcohol with $\mathrm{NaBH}_{4}$.

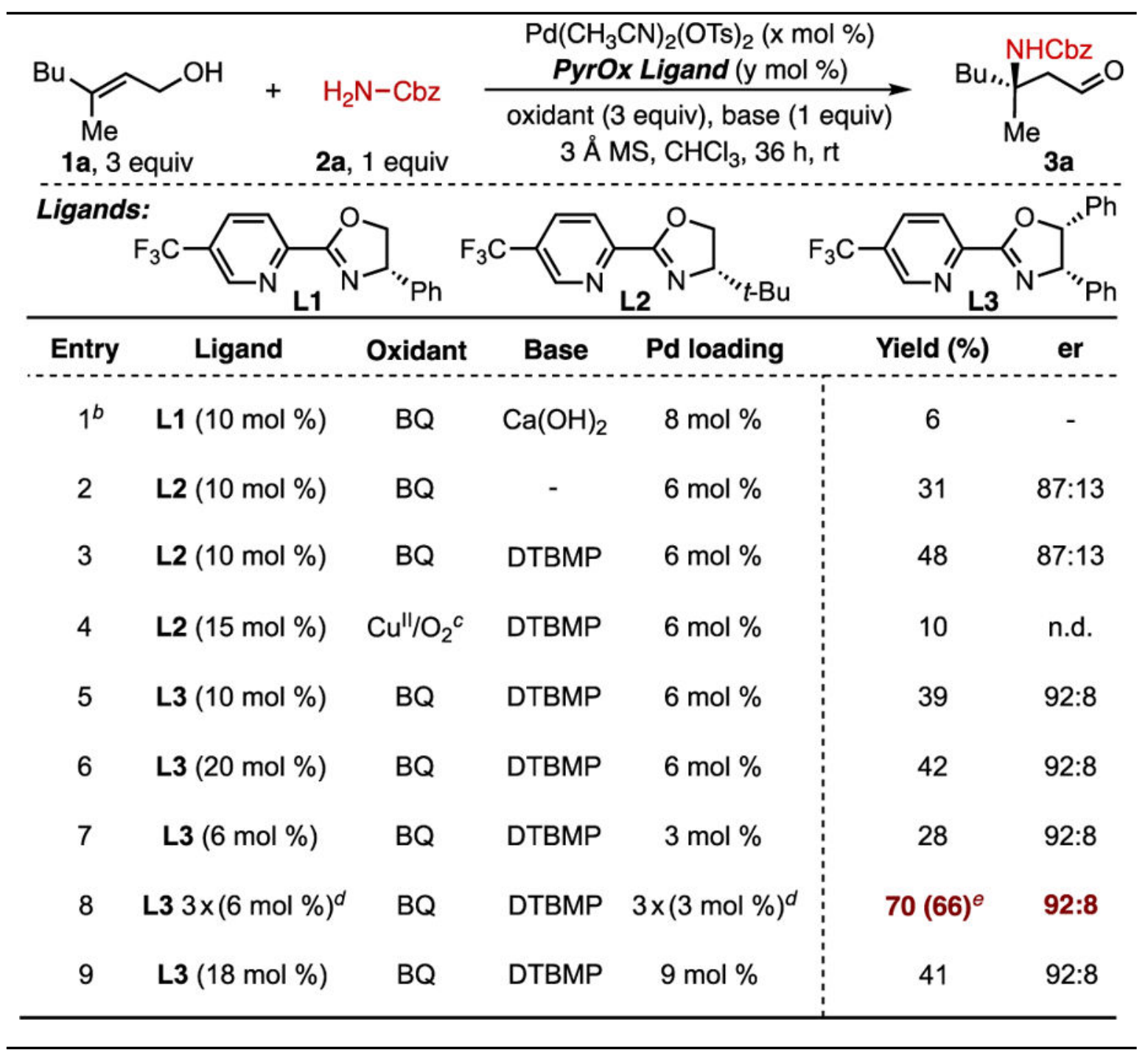




\section{Table 2:}

Substrate scope ${ }^{\mathrm{a}}$

${ }^{\text {a}}$ Each entry represents the average of two isolated yields on $0.3 \mathrm{mmol}$ scale. The er values were determined by SFC. ${ }^{b} Z$-alkenol used as olefin. ${ }^{c}$ Olefin synthesized in a 96:4 er with AD-mix-a, dr determined by ${ }^{1} \mathrm{H}$ NMR spectroscopy. ${ }^{\mathrm{d}}$ Olefin synthesized in a 97:3 er with AD-mix- $\beta$, dr determined by ${ }^{1} \mathrm{H}$ NMR spectroscopy. ${ }^{e} \mathrm{Pd}\left(\mathrm{CH}_{3} \mathrm{CN}\right)_{2}(\mathrm{OTs})_{2}(6 \mathrm{~mol} \%), \mathbf{L 3}$ PyrOx (14 mol \%), BQ (3 equiv), DTBMP (1 equiv), $3 \AA ̊ \mathrm{MS}$ (300 mg/ mmol), carbamate 2 ( 1 equiv) and alkene 1 (3 equiv) were stirred for $14 \mathrm{~h}$.

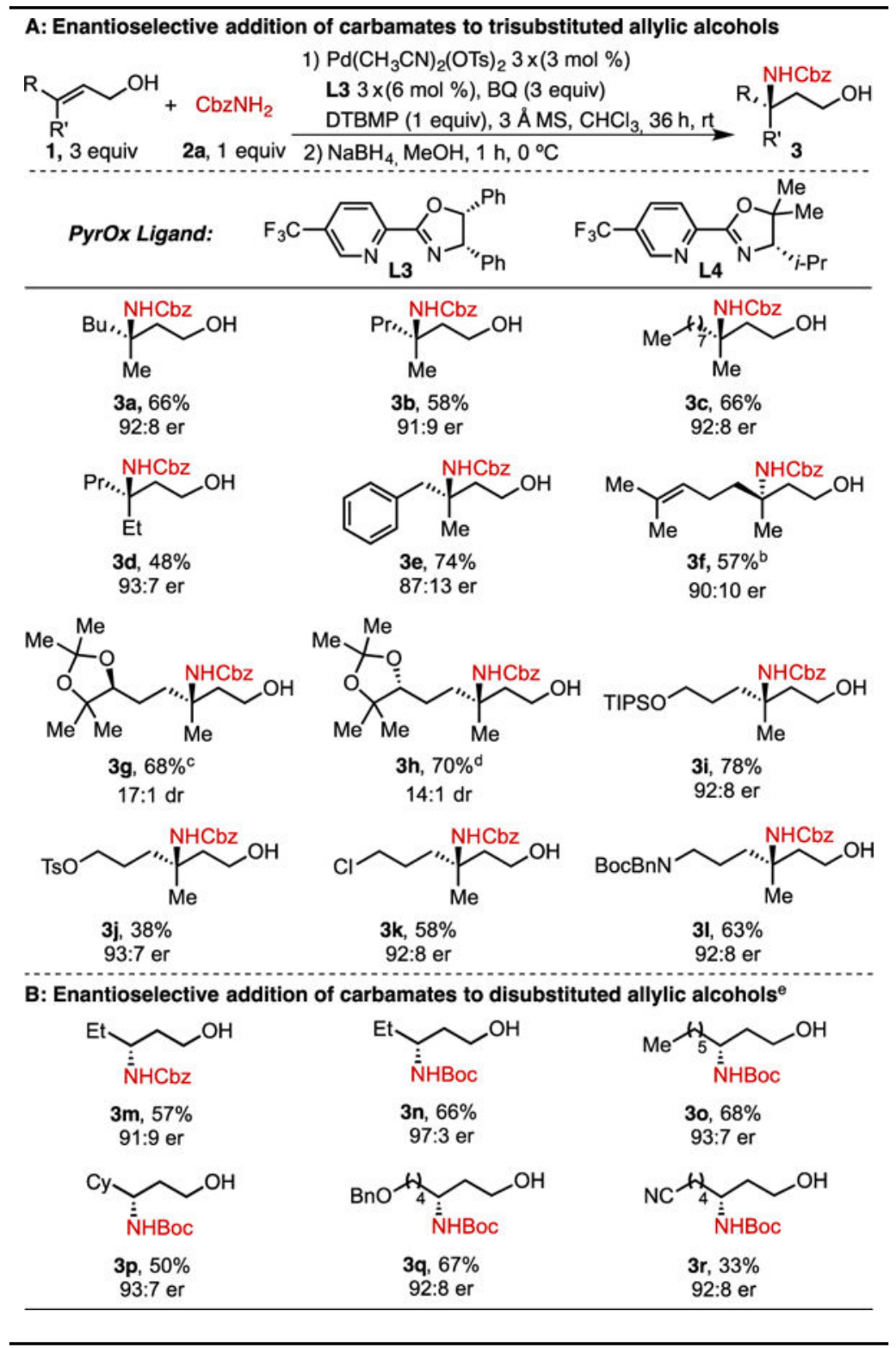

J Am Chem Soc. Author manuscript; available in PMC 2019 June 19. 
Table 3:

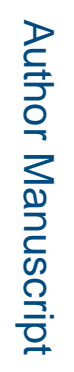

Synthesis of $\alpha$-secondary $\beta$-amino acids

\begin{tabular}{|c|c|c|c|c|}
\hline$\underbrace{\mathrm{NHCbz}}_{\mathrm{R}_{3}^{\prime}}$ & + & $\begin{array}{l}\mathrm{NalO}_{4} \\
4 \text { equiv }\end{array}$ & $\begin{array}{c}\mathrm{RuCl}_{3}(4 \mathrm{~mol} \%) \\
\mathrm{CCl}_{4}: \mathrm{CH}_{3} \mathrm{CN}: \mathrm{H}_{2} \mathrm{O}(1: 1: 1.2) \\
\mathrm{rt}, 2 \mathrm{~h}\end{array}$ & $\overbrace{\mathrm{R}^{\prime}{ }_{5}}^{\mathrm{NHCbz}}$ \\
\hline $\mathrm{Me} \mathrm{OH}$ & & & $\mathrm{Me} \mathrm{OH}$ & CbzHNi \\
\hline $\begin{array}{c}5 \mathrm{5a}, 96 \% \\
91: 9 \mathrm{er}\end{array}$ & & & $\begin{array}{c}\mathbf{5 b}, 92 \% \\
93: 7 \text { er }\end{array}$ & $\begin{array}{c}\mathbf{5 c}, 74 \% \\
93: 7 \mathrm{er}\end{array}$ \\
\hline
\end{tabular}

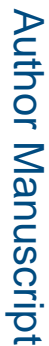

